\title{
QU
}

\section{ESTUDO DO CORPO D'ÁGUA DOS POÇO CARTESIANO NAS HORTAS COMUNITÁRIAS NO MUNICÍPIO DE NOVA CRUZ-RN}

\author{
PEREIRA, A. H. D. S. (IFRN-NC); SANTIAGO, A. F. J. (IFRN-NC); SILVA, A. C. O. (IFRN-NC)
}

Palavras Chave: condutividade elétrica, corpo d'agua, horta comunitaria

\section{INTRODUÇÃO}

O uso da água deve ser destinado de forma adequada. Conforme ANA (2007), "o consumo de água no Brasil distribui-se da seguinte forma: $46 \%$ na irrigação, $27 \%$ no consumo humano e $18 \%$ no consumo industrial."

As margens do rio Curimataú possui poço, que serve de irrigação para as hortas comunitárias no município de Nova Cruz. O estudo objetivou-se caracterizar o corpo de água, através de parâmetros físico-químico.

\section{METODOLOGIA}

Foram coletadas três amostras do poço, onde a medida da temperatura realizou-se "in loco" e fez uso do Termômetro Thermometer WT-1 $\left({ }^{\circ} \mathrm{C}\right)$, foram encaminhados ao laboratório do Campus Nova Cruz (IFRN), para ser avaliado o parâmetro condutividade elétrica, onde utilizou-se o condutivímetro TECNOPAN AC-200 $(\mu \mathrm{S} / \mathrm{cm})$.

\section{RESULTADOS E DISCUSSÕES}

Os dados das análises para caracterização do tipo de água são apresentados na tabela 1.

Tabela 1 - Valores da condutividade elétrica (CE) e temperatura

\begin{tabular}{|c|c|c|c|c|}
\hline \multirow{2}{*}{$\begin{array}{c}\text { Parâmetro físico- } \\
\text { químico }\end{array}$} & \multicolumn{3}{|c|}{ Amostra } & \multirow{2}{*}{ VMP } \\
\cline { 2 - 4 } & $\mathbf{0 0 1}$ & $\mathbf{0 0 2}$ & $\mathbf{0 0 3}$ & \\
\hline Temperatura $\left({ }^{\circ} \mathrm{C}\right)$ & 26.4 & 26.1 & 26.2 & - \\
\hline $\mathrm{CE}(\mu \mathrm{S} / \mathrm{cm})$ & 1.708 & 1.703 & 1.708 & 0 e 750 \\
\hline
\end{tabular}

A temperatura da água, pode-se observar um padrão de comportamento semelhante, cujas variações de leitura foram diretamente influenciadas pelas condições atmosféricas.

De acordo com Richards (1954) apud Almeida (2010), o corpo de água com valores de CE entre 750 e $2250 \mu \mathrm{S} / \mathrm{cm}$ a $25^{\circ} \mathrm{C}$ pertence a água de alta salinidade, ou seja ela refere-se ao corpo de água salina, impróprio para uso na irrigação, de acordo com o CONAMA (2005).

\section{CONCLUSÃO}

De acordo com os dados obtidos neste trabalho pode-se estabelecer que o tipo do corpo de água avaliado se enquadra na classe de água salina.

\section{REFERÊNCIAS}

${ }^{1}$ Agência Nacional das Águas - ANA. Consumo de água no Brasil. Brasília, 2007. Disponível em: <http://www.ana.gov.br> Acesso em: 08 ago 2014.

2 CONSELHO NACIONAL DO MEIO AMBIENTE [CONAMA]. Resolução $n^{\circ} 357$ de 17 de Março de 2005. Dispõe sobre a classificação dos corpos de água e diretrizes ambientais para o seu enquadramento, bem como estabelece as condições e padrões 27 de lançamento de efluentes, e dá outras providências. [S.I.: s.n.], 2005.

${ }^{3}$ ALMEIDA, Otavio Alvares de. Qualidade da água de irrigação. 1. ed. Cruz das Almas: Embrapa Mandioca e Fruticultura, 2010. 